\title{
Right Ventricular Fatty Infiltration Associated with Cardiac Sudden Death
}

\author{
Yoshiaki Kaneko, Tadashi Nakajima, Tadanobu Irie and Masahiko Kurabayashi
}

Key words: right ventricular fatty infiltration, cardiac sudden death

(Intern Med 52: 635-636, 2013)

(DOI: 10.2169/internalmedicine.52.7784)

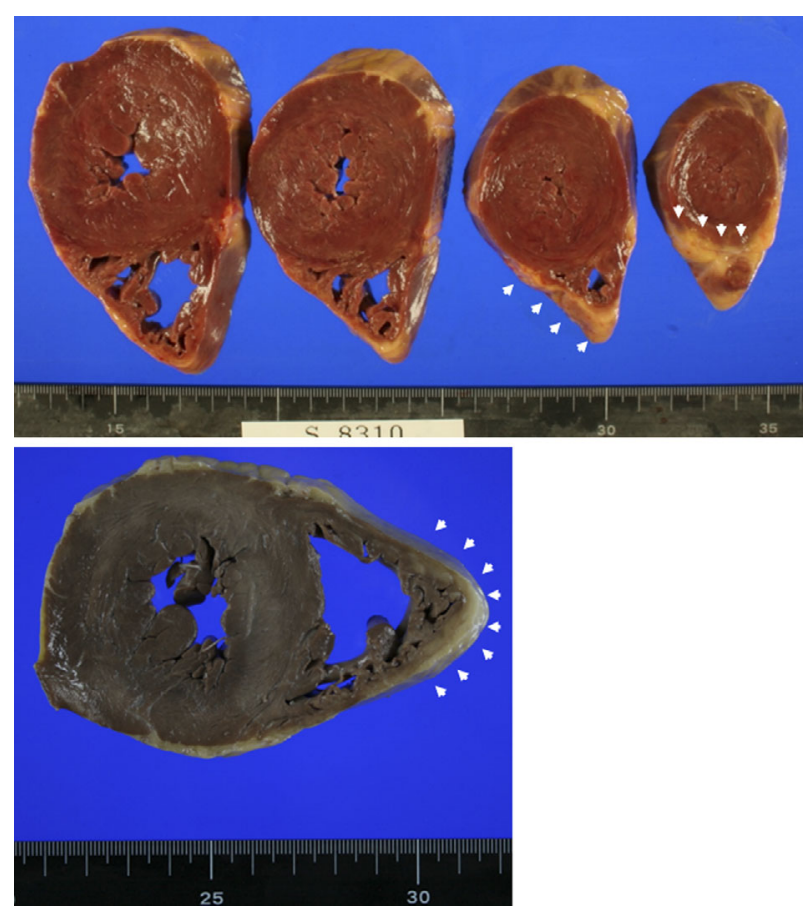

Picture 1.

A 47-year-old man with no previous history of cardiovascular disease and no family history of sudden death suffered from sudden onset of syncope due to ventricular fibrillation (VF) which developed after mild exercise in the early morning and was also confirmed on automated electrical defibrillator recordings (data not shown). The clinical data, including the results of 12-lead ECG performed before the development of VF and echocardiogram, were not available. The patient died of VF after being unsuccessfully defibrillated, and a post-mortem examination was performed. The weight of the heart was $440 \mathrm{~g}$. Visual inspection revealed mild thinning of the right ventricular (RV) free wall and a fatty infiltration in the apical region of the RV free wall without RV

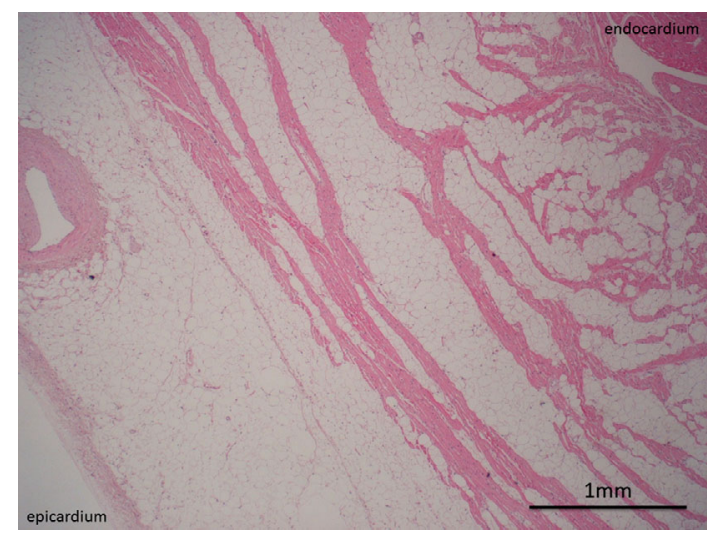

Picture 2.

dilatation (arrowheads in Picture 1). A microscopic examination revealed no pathological findings suggesting acute coronary ischemia or acute-subacute myocyte necrosis, which is frequently observed in the early stages of arrhythmogenic RV cardiomyopathy. However, partial transmural fatty filtration without fibrosis was observed (Picture 2), which differed from the situation in normal hearts and typical arrhythmogenic RV cardiomyopathy (ARVC) (1), and may have been the cause of sudden cardiac death in this case (2). We did not perform an immunohistochemical analysis of plakoglobin (gannma-catenin), a desmosomal protein evaluated in diagnostic tests for ARVC.

The authors state that they have no Conflict of Interest (COI).

\section{References}

1. Burke AP, Farb A, Tashko G, Virmani R. Arrhythmogenic right ventricular cardiomyopathy and fatty replacement of the right ventricular myocardium: are they different diseases? Circulation 97: 1571-1580, 1998. 
Intern Med 52: 635-636, 2013 DOI: 10.2169/internalmedicine.52.7784

2. Thiene G, Nava A, Corrado D, Rossi L, Pennelli N. Right ventricular cardiomyopathy and sudden death in young people. $\mathrm{N}$
Engl J Med 318: 129-133, 1988.

(C) 2013 The Japanese Society of Internal Medicine http://www.naika.or.jp/imonline/index.html 